\title{
Raul Brandão na revista Seara Nova
}

\author{
Raquel S. Madanêlo Souza1
}

RESUMO: Raul Brandão, considerado por muitos críticos como um dos mais importantes escritores da literatura portuguesa do início do século $\mathrm{XX}$, foi um dos diretores da revista Seara Nova entre 1921 e 1923. Ele publicou nesse periódico, trechos de alguns de seus livros já editados e de outros inéditos, até então. O objetivo desse ensaio é destacar qual a relação do escritor com o projeto seareiro e qual o papel da literatura nessa revista de "Doutrina e Crítica”, entre os anos de 1921 e 1926.

ABSTRACT: Raul Brandão, considered by many critics as one of the most important writers of the Portuguese literature in the beginning of XX century, was one of the directors of Seara Nova magazine from 1921 to 1923. This essay intends to analyze his texts published or edited at this publication, trying to think about the relation between the seareiro project and the meaning of the social function of literature at this "Doutrina e Crítica" magazine, from 1921 to 1926.

PALAVRAS-CHAVE: Revista Seara Nova; Raul Brandão; Literatura.

KEYWORDS: Seara Nova Magazine; Raul Brandão; Literature.

A revista Seara Nova foi lançada em Lisboa no dia 15 outubro de 1921. Criada pelo "Grupo da Biblioteca Nacional"2, essa publicação tinha como foco principal a promoção de uma reforma da mentalidade portuguesa, através da crítica e análise da situação educacional, política, econômica e social do país; da proposição de soluções para essas questões relacionadas à crise nacional e de uma tentativa de ação reformadora, de caráter pedagógico-doutrinário.

A iniciativa de criar essa publicação de "Doutrina e Crítica" surgiu em reuniões organizadas por alguns elementos dissidentes da sociedade

\footnotetext{
${ }^{1}$ Doutoranda em Estudos Comparados de Literaturas de Língua Portuguesa, FFLCHUSP. Pesquisa: Convergências e Divergências: Revistas literárias em perspectiva - A Águia, Seara Nova e Terra de Sol.

2 Grupo de intelectuais portugueses que se reunia na Biblioteca Nacional de Lisboa entre 1919 e 1927. Dentre esses intelectuais estavam: Jaime Cortesão, Raul Proença, Raul Brandão, Aquilino Ribeiro, Câmara Reis e Augusto Casimiro.
} 
"Renascença Portuguesa"3, em conjunto com outros membros da intelligentsia lusitana, que se reuniam no gabinete do então diretor da Biblioteca Nacional de Lisboa ${ }^{4}$. Este grupo de intelectuais era formado por: Aquilino Ribeiro, Augusto Casimiro, Faria de Vasconcelos, Ferreira de Macedo, Francisco Antonio Correia, Jaime Cortesão, José Azeredo Perdigão, Câmara Reys, Raul Brandão e Raúl Proença, os quais fizeram parte, todos juntos, do corpo diretivo da Seara Nova até o ano de 1923.

Cientes da grave situação do país e intentando apresentar projetos de reestruturação nacional, esses homens buscaram fazer desse periódico um espaço para a discussão de temáticas que giravam em torno de doutrinas políticas e sociais; problemas morais e filosóficos; educação; crítica social; história; crítica literária, crítica artística e teatral, dentre outros assuntos, havendo um espaço reservado também à publicação de textos literários em prosa e em verso.

A postura desse grupo, frente à situação do país, ficou expressa no editorial ${ }^{5}$ da revista, escrito ${ }^{6}$ por Raúl Proença, mas que não aparece assinado por ele dentro do periódico. Nesse texto, buscava-se mostrar qual a função da publicação e de sua entrada no cenário português e qual o papel da elite intelectual no projeto que ali se delineava. Estes mesmos intelectuais assumiram-se como responsáveis, ao lado dos políticos, pela crise nacional e apostavam na apresentação de projetos para a solução do chamado "desastre coletivo" 7. Para tanto, o objetivo do grupo seareiro ${ }^{8}$ seria o de transformar os intelectuais em membros ativos no processo de reestruturação da pátria: "Serão poetas militantes, críticos militantes, economistas e pedagogos militantes. (...)

\footnotetext{
3 A "Renascença Portuguesa" foi uma sociedade criada em 1911 que se formou em torno de um programa de promoção da cultura e da educação.

4 Jaime Cortesão tornou-se diretor da BN de Lisboa em 1919, permanecendo no cargo até 1927.

${ }^{5}$ Editorial publicado no primeiro exemplar da revista, de 15 de Outubro de 1921.

6 REIS, 1985.

7 SEARA NOVA, out. 1921.

8 "O grupo (...) começou as suas reuniões cerca dum ano antes da publicação do primeiro número(...) e dele fizeram parte desde individualidades conservadoras até elementos operários, jornalistas, professores, escritores, advogados, funcionários, médicos,(...). Durante as primeiras sessões, deu-se logo a eliminação, (...), de certos elementos sem afinidades espirituais" (REIS, 1985, p.17).
} 
Muito tempo passaram já os homens de elite isolados do povo, fora das realidades sociais, muito para além do plano e do movimento em que se tece o futuro do mundo" 9. Por esse breve trecho do editorial é possivel perceber que o uso repetido do adjetivo "militante", para caracterizar seja economistas, seja pedagogos, seja os poetas, revela o peso da idéia de "ação" no programa de reforma proposto naquele momento. E essa mesma ação, quando pensada em relação ao campo literário ${ }^{10}$, nesse contexto, implica a entrada em uma temática fundamental do campo da estética: a chamada função da arte. Lendo a Seara, é possível perceber que essa questão apareceu na revista, de maneira não sistemática, mas com alguma recorrência, em artigos publicados nesse periódico lisboeta.

Segundo o filósofo italiano Luigi Pareyson: "Há uma arte que quer ser empenhada, militante, engagé, que quer difundir uma determinada concepção religiosa, política, social” ${ }^{11}$, e que buscaria se definir em oposição a uma suposta arte que, ao contrário dessa primeira, pretenderia "ser forma pura" 12 . Sendo assim, não só a atuação do grupo seareiro em campos não-artísticos pretendia ser engajada, no sentido de filiada a um programa e atuante na reforma da nação, mas seu julgamento da literatura e da arte, como um todo, acaba, em alguns momentos, sendo pensado em termos da necessidade de desempenhar uma determinada função social dentro do contexto de crise de Portugal.

Sobre essa produção literária presente na Seara Nova, em seus primeiros anos de publicação ${ }^{13}$, pode-se afirmar que era bastante diversificada e contava com um número variado, também, de escritores publicados; porém, a parte da publicação dedicada à Prosa, entre 1921 e 1923, tinha como seu mais assíduo colaborador o português Raul Brandão. Este singular escritor lusitano fez parte da diretoria da

\footnotetext{
9 SEARA NOVA, out.1921, p.1.

10 BOURDIEU, 2005.

11 PAREYSON, 2001, p.39.

12 PAREYSON, 2001, p.39.

13 Minha pesquisa sobre a Seara Nova resume-se apenas aos anos de 1921 a 1926, em que o projeto do grupo seareiro era o de restaurar a República e contribuir para o "renascimento" do país. Após o Golpe Militar de 28 de Maio, os esforços do grupo se centraram no restabelecimento da democracia em Portugal.
} 
revista, e nela editou trechos de algumas de suas obras já publicadas anteriormente e de outras inéditas até então. Em seu percurso por esse periódico, ele inseriu trechos de: A Morte do Palhaço; vários excertos do primeiro volume das Memórias, de 1919 e algumas partes de livros, como Os Pescadores e o volume II das suas Memórias, divulgados na revista antes de saírem em livro. Além de colaborar como prosador, Brandão contribuiu com dois textos na seção de Crítica Literária, fazendo apreciação de duas obras de seu amigo, o poeta Teixeira de Pascoaes e publicando um texto, que de fato fazia parte das Memórias, em uma seção da revista dedicada à História.

Sua participação na Seara, que é apenas rapidamente citada em alguns estudos sobre esse escritor, e também em estudos sobre a história do próprio periódico, parece relacionar-se diretamente à preocupação do grupo seareiro com as questões sociais em Portugal.

Um dos aspectos mais notados e recorrentemente comentados acerca da obra de Raul Brandão é, certamente, a presença constante, em sua produção escrita, de temáticas de forte conotação social ${ }^{14}$. Seja no sentido de desconcerto do mundo, que perpassaria grande parte da literatura portuguesa desde os trovadores, como observou Maria Helena Nery Garcez ${ }^{15}$ em sua leitura de Os Pobres; seja no sentido de uma sobrevalorização da carência ou até mesmo de um "neofranciscanismo", como afirmou Vítor Viçoso ${ }^{16}$, em estudo introdutório a essa mesma obra; seja como "consciência de justiça social17", como destacou Álvaro Manuel Machado ${ }^{18}$ em seu reconhecido trabalho Raul Brandão - entre o Romantismo e o modernismo: todos esses estudiosos da literatura são unânimes em destacar a presença e até, diria, a insistente análise dos

\footnotetext{
14 “(...) após a viragem do século, encontramos Raul Brandão em Lisboa, absorvido pelo mundo do jornalismo, nas colunas do Correio da Manhã e de O Dia, mundo que o introduz na análise dos problemas sociais, que serão uma constante em sua obra" (RIBEIRO, 1990, p. 14).

15 GARCEZ, 1985, p.27.

16 VIÇOSO, 1984.

17 MACHADO, 1984, p.75.

18 MACHADO, 1984.
} 
problemas da sociedade nos textos literários, jornalísticos e, até mesmo, autobiográficos desse escritor.

O primeiro texto de Brandão publicado na Seara Nova, intitulado “Sombras Humildes”, fazia parte do volume I das suas Memórias. Neste excerto, os homens e mulheres do campo são descritos como pessoas carentes, que mal tinham o pão para alimentá-las e que sofriam com o problema da fome. Em outro trecho das Memórias, intitulado: "O homem que veio a Lisboa pregar Deus ao sr. Afonso Costa”, mais uma vez, a questão da injustiça e da exclusão social é diretamente abordada. Esse "homem", parece servir, no citado texto, para exemplificar o abismo que separava o povo das decisões políticas e para permitir a denúncia da impossibilidade de pessoas comuns, sem voz ativa na sociedade, explicarem que queriam apenas "mais justiça e mais pão"19.

Em "Retratos de Desconhecidos", que viria a sair no volume II das Memórias, alguns anos depois, além de descrever pessoas simples que faziam parte de seu pensamento do passado, o escritor descreve um pobre ladrão que ele encontrara pelo caminho e que sofria por ter uma filhinha doente a quem não conseguia alimentar; neste texto ele denuncia a corrupção em Portugal e insere-se no contexto da injustiça social dominante, assumindo, também para $\mathrm{si}^{20}$, a responsabilidade pela situação vigente no país ${ }^{21}$.

Seja nestes escritos autobiográficos das Memórias ${ }^{22}$, seja em escritos ficcionais, a situação de injustiça e desigualdade social sofrida pelos humildes e a dor de viver parecem povoar grande parte dos textos do escritor. Os trechos de A Morte do Palhaço, que foram publicados na revista, traziam figuras de excluídos da sociedade. Entre os excertos dessa obra, um, em especial, merece mais atenção: o texto "Primavera

\footnotetext{
19 BRANDÃO, nov. de 1921, p.74.

20 Note-se que os intelectuais assumiram, no editorial da Seara Nova, a culpa pelos problemas do país.

21 "Ele é ladrão, mas nós somos piores do que ele - somos piores do que ladrões". BRANDÃO, março de 1924, p.174.

22 “(...) as suas Memórias constituem essencialmente um relato, misto de política, crítica social e moral e pinceladas de um quotidiano que não muitas vezes é diretamente o seu” . RIBEIRO, 1990, p.12.
} 
Abortada" que seria, na realidade, uma adaptação de outro conto originalmente intitulado "A Voluptuosidade e o Amor"23, que fizera parte de A História dum Palhaço, de 1896. Este texto, inserido no periódico, parece $^{24}$ ter sido totalmente modificado pelo escritor e adaptado para o novo contexto em que se inseriu.

Ao comparar esse conto que saiu na Seara Nova ao que foi publicado, anos mais tarde, em edição de A Morte do Palhaço, em 1926, percebem-se diferenças significativas entre os dois textos. Em primeiro lugar, a versão publicada na revista é mais curta que a publicada em livro; além disso, e mais importante ainda, percebe-se que o foco dos dois textos incide sobre diferentes elementos: na versão de 1922, eram as crianças russas ${ }^{25}$ que mereciam a atenção do narrador em primeira pessoa. No texto de 26, o personagem principal era um Deus sinistro que dominava um país e vivia de se alimentar da tristeza e, principalmente ${ }^{26}$, do sentimento de dor ${ }^{27}$.

Sobre a citada denúncia da condição da infância russa, abortada pela situação de penúria do país, naquele momento histórico, é importante destacar que se tratava de uma campanha, que surgira na revista lisboeta, com a finalidade de promover a recolha, e posteriormente o envio de dinheiro para os "Famintos Russos"28.

23 Segundo João Pedro de Andrade: "O conto A Voluptuosidade e o Amor, página das mais belas e, ao mesmo tempo, das mais equilibradas que saíram de sua pena, transforma-se num escrito híbrido, Primavera Abortada, com um final de circunstância (a fome que avassalou a Rússia em 1922), declamatório e substituindo o êxtase lírico do conto primitivo". Há, porém, um dado incorreto nesta abordagem de Andrade. "Primavera Abortada", inserido em livro, em 1926, não faz nenhuma referência à situação das crianças russas; a referência a essa situação foi publicada na Seara Nova, em 1922.

24 Não tivemos acesso à primeira versão de "A Voluptuosidade e o Amor", disponível apenas na Biblioteca Nacional, em Lisboa.

25 "Também agora mesmo, nesta noite esplêndida e impassível, morrem aos milhares as crianças russas e ninguém as ouve gritar". BRANDÃO, agosto de 1922, p.62.

26 "O Deus sustentava-se de Dor" (BRANDÃO, 1926, p. 104).

27 "Só a dor existe, só a dor cega e sem boca para gritar, que neste mundo extraordinário se estorce" (BRANDÃO, 1926, p. 105). A dor é um dos topos recorrentes na literatura de Brandão, como observa Álvaro Manuel Machado.

28 "Raul Brandão retoma aí muito do que ficara suspenso no texto de 1894-95. Perante a realidade histórica duma revolução cujas premissas ideológicas eram as do ateísmo, as dum desafio absoluto da Idéia perante Deus, e também as dum messianismo nacionalista russo que se originara num anarquismo, Raul Brandão volta a defender uma posição humanista e religiosa oposta às ideologias 
Ainda dentro da temática social, na literatura de Brandão inserida nas páginas da revista, podemos citar a publicação de trechos de Os Pescadores, obra ainda inédita em livro, no momento de sua edição na Seara Nova. Apesar da evidente mudança de perspectiva e coloração da sua narrativa nessa obra que é bastante mais "diurna", como afirma Maria da Conceição Ribeiro, há nela a descrição dos humildes em sua "faina cotidiana" 29.

Evidentemente, a questão social não é o único aspecto notável na escrita de Brandão, escritor tão importante da literatura portuguesa por sua preocupação com a estética das suas obras que primam por uma moderna fragmentação estrutural e por uma abordagem significativamente peculiar e particular de alguns símbolos e arquétipos temáticos recorrentes que circulam por seus escritos. Porém, podemos afirmar que é essa consciência de justiça na sociedade que o aproxima e filia, certamente, à Seara Nova ${ }^{30}$.

Como dissemos anteriormente, a presença de Brandão na revista, apesar de pouco notada e pouco comentada pela crítica e pelos estudiosos de sua obra, tem relação com a chamada função da literatura - seja no sentido do questionamento que se insere em alguns $\operatorname{artigos}^{31}$ da revista, seja na forma como a própria publicação passa lida com o texto literário entre 1921 e 1926. A Seara parece ter aberto em suas páginas um espaço para esse questionamento da função literária dentro da sociedade, discussão essa que ganharia corpo anos depois, dentro da cultura portuguesa, a partir do chamado neo-realismo.

'sobrehumanas' (...)” (MACHADO, 1984, p. 38).

${ }^{29}$ RIBEIRO, 1990, p. 31.

30 “(...) terá sido igualmente no âmbito das suas preocupações com a pobreza e com a injustiça social que se terá ligado ao movimento da Seara Nova, veículo de toda uma proposta de renovação político-ideológica, mental e social”. RIBEIRO, 1990, p.32.

31 Um bom exemplo da questão social dentro da Seara Nova é o um texto de Raul Proença sobre o raid aéreo de Sacadura Cabral e Gago Coutinho. Proença afirma: "Uma nação inteira não consagra um poeta, só porque faz lindos sonetos; (...). É necessário que esses sonetos, esses livros, esses quadros tenham um sentido, (...) um valor nacional; que eles exprimam ou o que há de mais alto no caráter dum povo, ou o que há de mais profundo e legítimo nas suas aspirações, ou o que lhe indica melhor o caminho do futuro" (PROENÇA, n.16, 1 de ago. de 1922, p.59). 
A saída de Brandão da diretoria, em 23, coincide com a mudança no corpo diretivo geral dessa publicação e com uma mudança de postura do periódico frente a cada vez mais problemática situação do país. Com isso, a literatura vai desaparecendo gradativamente das páginas dessa publicação e é possível notar que a partir do biênio 19251926, quando a revista se torna semanal, ocorre quase que o desaparecimento dos textos literários e artísticos deste semanário, havendo nesse período específico, um número muito maior de textos de doutrinação e crítica.

Podemos concluir, portanto, por essa breve análise, que a presença de Brandão como principal prosador, nos primeiros anos da revista, é reflexo de uma confluência entre a preocupação social tão recorrente em suas obras literárias, jornalísticas e autobiográficas e o projeto de uma literatura participante desenvolvido na revista Seara Nova,fazendo parte de uma discussão, que se estabelecera naquele periódico, acerca da autonomia e função da literatura. E concluímos, também, que sua saída da revista e o progressivo desaparecimento dos textos literários ${ }^{32}$ de dentro da publicação - a partir de 1925 até agosto de 1926 - constituem uma opção do grupo seareiro pela via de crítica social e doutrinação, que vai se tornando cada vez mais central nessa revista à medida que as crises política, econômica e social se ampliavam no Portugal pré Ditadura Militar, de maio de 1926.

\section{Referências bibliográficas}

ANDRADE, João Pedro de. Raul Brandão. Lisboa: Arcádia Editora, 1963.

BRANDÃO, Raul. "O homem que veio a Lisboa pregar Deus ao sr. Afonso Costa”. Seara Nova, Lisboa, n.3, v.1, 20 de nov. de 1921. . Primavera Abortada. In Seara Nova, Lisboa, 16: 62, 1 de ago. 1922.

\footnotetext{
32 A Literatura e a arte desaparecem das páginas da Seara Nova entre 1925 e agosto de 1926 ( em função da censura, a revista sofre a primeira interrupção em agosto, e só retoma as atividades em 1927). É importante salientar, porém, que após o golpe militar e a retomada da publicação, em 27 - período que ultrapassa nossos objetivos de estudo - há um aumento da presença de produções literárias e culturais na revista, já que o espaço dedicado à doutrinação e crítica política passa a ser visado pela censura e é, assim, substituído por textos do campo artístico.
} 
- Primavera Abortada. In A Morte do Palhaço e o Mistério da Árvore. Lisboa: Seara Nova, 1926.

. "Retratos de Desconhecidos". Seara Nova, Lisboa, 33, 20 de mar. 1924.

BOURDIEU, Pierre. As Regras da Arte. $2^{\mathrm{a}}$ ed. São Paulo: Companhia das Letras, 2005.

GARCEZ, Maria Helena Nery. Sinfonia Desconcertada: uma leitura de Os Pobres de Raul Brandão. In Boletim Informativo: Publicação do CEP da USP, São Paulo, $3^{\mathrm{a}}$ série, ano XI, 1: 27-34. 1985.

MACHADO, Álvaro Manuel. Raul Brandão entre o Romantismo e o Modernismo. Lisboa: Biblioteca Breve, 1984, v. 88.

MAGALHÃES, José de. Seara Nova. Lisboa, 14, 12 de mai. 1922.

PAREYSON, Luigi. Problemas da Estética. São Paulo: Martins Fontes, 2001.

PROENÇA, Raul. Seara Nova, Lisboa, n.16, 1 de ago. 1922.

RIBEIRO, Maria da Conceição. Raul Brandão - Um Labirinto Trágico (Estudo e antologia). Lisboa: Alfa, 1990, p.9-43.

REIS, Câmara. Raul Proença. Lisboa: Biblioteca Nacional, 1985.

SEARA NOVA. "Editorial”. Seara Nova, Lisboa, n.1, v. 1, 15 de out. 1921.

TRAVESSA, Elisa Neves. Jaime Cortesão - Política, História e Cidadania (1884-1940). Porto: Edições ASA, 2004.

VIÇOSO, Vitor. "Os Pobres: um dolorismo redentor". In BRANDÃO, Raul. Os Pobres. Lisboa: Editorial Comunicação, 1984, p.9-31. 